\title{
The effect of the dynamics of external load changes in the aspect of the lower limit response time of the competitors of mixed martial arts (MMA) taking into account weight categories and sport experience
}

Authors' Contribution: A Study Design B Data Collection C Statistical Analysis D Data Interpretation E Manuscript Preparation F Literature Search G Funds Collection

\author{
Angelina Ignatjeva ${ }^{1}$ ABCDEF, Magdalena Nitychoruk ${ }^{1}$ ABCDE, Artur Terbalyan ${ }^{1}$ BDEF, \\ Alan Langer ${ }^{1 \text { BDEF }}$ Agata Wacek ${ }^{1}$ CDEG, Adam MaszCzyk ${ }^{2}$ CDEG \\ ${ }^{1}$ Department of Sport Theory, \\ The Jerzy Kukuczka Academy of Physical Education, Katowice, Poland \\ 2 Institute of Sport Sciences, \\ The Jerzy Kukuczka Academy of Physical Education, Katowice, Poland
}

abstract

Background: The main aim of this study is to analyze the influence of the external load on the reaction time of the lower limbs of mixed martial arts fighters.

Material and methods:

The research group consisted of 31 senior MMA fighters (with training experience of at least 10 years, divided into two weight categories: light $(66-70 \mathrm{~kg}$ ) and heavy (over $93 \mathrm{~kg}$ ) and each of them into two categories: intermediate and advanced). The Keizer Leg Press pneumatic device (Keizer, Fresno, CA, USA) was used to evaluate the reaction time of the lower limbs of MMA fighters. The subjects performed a 20-minute warm-up and then worked on the Keizer Leg Press measuring device according to the manufacturer's protocol. Based on this data, a 10 single repetitions test was performed. The value of the external resistance and the time to the next repetition were not changed to obtain the measurement data.

Results: The obtained results indicate a constant deterioration of the value of the $\mathrm{RT}_{L \mathrm{BL}}$ and $\mathrm{RT}_{L}$ variable when increasing the external load in both studied groups. In the case of advanced players in the 66-70 $\mathrm{kg}$ weight group, a clear (statistically significant) increase in the value of the $\mathrm{RT}_{L \mathrm{BL}}$ and $\mathrm{RT}_{\perp}$ variable occurred from $70 \% 1 \mathrm{RM}$, while in the intermediate group it was from 50\% 1RM, and from $80 \% 1 \mathrm{RM}$ in the weight category above 93 in both study groups. Growth dynamics was lower in the advanced group in both tested weight categories.

Conclusions: Performing the progression of the external load may allow the detection of the dominance of one lower limb and determination of the dynamics of differences in the reaction time of the frontal and back limb in MMA fighters.

Key words: mixed martial arts, training, external load, reaction time.

\section{article details}

Article statistics:

Full-text PDF:

Copyright

Indexation:

Funding:

Conflict of interests:

Corresponding author:

Open Access License:

Word count: 2,810; Tables: 5; Figures: 4; References: 23

Received: March 2021; Accepted: March 2021; Published: June 2021

http://www.balticsportscience.com

(c) Gdansk University of Physical Education and Sport, Poland

Celdes, Clarivate Analytics Emerging Sources Citation Index (ESCI), CNKI Scholar (China National Knowledge Infrastructure), CNPIEC, DOAJ, EBSCO - Central \& Eastern European Academic Source, EBSCO - SPORTDiscus, EBSCO Discovery Service, Google Scholar, Index Copernicus, J-Gate, Naviga (Softweco, Primo Central (ExLibris), ProQuest - Family Health, ProQuest - Health \& Medical Complete, ProQuest - Illustrata: Health Sciences, ProQuest Nursing \& Allied Health Source, Summon (Serials Solutions/ProQuest, TDOne (TDNet), Ulrich's Periodicals Directory/ ulrichsweb, WorldCat (OCLC)

This research received no specific grant from any funding agency in the public, commercial, or not-for-profit sectors. Authors have declared that no competing interest exists.

Magdalena Nitychoruk - Department of Sport Theory, The Jerzy Kukuczka Academy of Physical Education, Katowice, Poland, e-mail: magda.aneta.krawczyk@gmail.com; phone number: +48-518-443-073

This is an open access article distributed under the terms of the Creative Commons Attribution-Non-Commercial-NoDerivatives 4.0 International (https://creativecommons.org/licenses/by-nc-nd/4.0/), which permits use, distribution and reproduction in any medium, provided the original work is properly cited, the use is non-commercial and is otherwise in compliance with the license. 


\section{INTRODUCTION}

Mixed martial arts (MMA) is a full combative sport with a global increase in popularity. MMA has been characterized by a combination of actions of high intensity and short duration such as striking and grappling. These actions highlighted the need for high levels of muscle power [1] - of both upper and lower limbs - and muscle strength - both dynamic [2] and isometric [1] - as well as high levels of muscular and aerobic endurance [3]. In a methodologically correct MMA training action, the basis is to raise the functional level of strength motor skills first, then speed, endurance and coordination skills. These abilities in combat are significantly correlated with the reaction time, which can be defined as the time elapsing from the stimulus to the initiation of movement [4-6]. Reaction time is an important element in athletes' preparation, a significant factor in the speed of movement, and fundamental in achieving sports success. In MMA, the reaction time depends on the visual stimulus caused by the opponent's action. During a fight, the competitor must simultaneously and constantly try to decode the rival in terms of the attack strategy, as well as his movements in terms of defense or counterattack [7-8]. Moreover, during a fight, competitors must perform movement tasks not only with extreme precision, but also under time pressure [9]. The high variability and high intensity of physical exertion during combat lead to physical and mental fatigue. The player's low resistance to physical fatigue plays a huge role in a failure situation. In the absence of adequate fitness, at some point the technique begins to fail, and the technical instructions from the trainer become more and more difficult to perform [10]. Gradual resistance muscle strength training increases muscle strength, speed and endurance in a safe manner and allows muscles to accustom to the weight. Appropriate strength preparation of the lower limbs in mixed martial arts fighters enables achieving a high level of leg speed, and consequently, to perform effective attacks, avoiding the opponent's blows. Unfortunately, in MMA training, both lower limbs are often not taken into account, and repetitive, asymmetric loads are practiced, which may lead to muscle imbalance and increase a risk of injury [11].

Measurement of reaction time is an important tool in determining the percentages of the resistance at which the peak fatigue moment is exceeded, when the athlete's movement becomes noticeably slower with his reaction to resistance. Increasing the resistance may allow detection of the dominance of one lower limb and determination of the dynamics of differences in the reaction time of the frontal and back limb in MMA fighters.

The main aim of this study was to analyze the influence of resistance on the reaction time of lower limbs of mixed martial arts fighters. This problem was considered in terms of weight categories and the sports level of MMA fighters. Undertaking this research is justified by the limited amount of data on the influence of resistance on the reaction time of the lower limbs. It is also difficult to find information, taking into account these variables, with regard to the position of the lower limbs, namely the front and back limbs. The research results are intended to optimize the training process among intermediate and advanced MMA fighters, in weight categories 66-70 kg and over 93.

\section{MATERIAL AND METHODS}

\section{Characteristics OF THE STUdied GROUP}

The research group consisted of 31 men with training experience of at least 10 years. The subjects were divided into two weight categories: light (66-70 kg) and heavy (over 93 $\mathrm{kg}$ ). The system of selecting fighters for research was mixed. The classification of fighters was developed on the basis of the Ranking of Polish MMA Fighters. In the course of the research, 3 fighters were eliminated due to injuries and contusions. 14 competitors were qualified for each weight category. The research was conducted in the starting period. 


\section{IEST METHODS}

The Keizer Leg Press pneumatic device (Keizer, Fresno, CA, USA) was used to evaluate the reaction time of MMA fighters' lower limbs. The device allows measuring the reaction time independently for both lower limbs with simultaneous registration of the speed of obtaining this variable. The Keizer Leg Press A420 series measures individual variables over the entire range of motion. The machine allows for individual registration of the number of repetitions of the exercise of the following variables: reaction time [s], peak power [W], force level at which the maximum power was obtained [N], maximum single load (CM, 1RM). The body weight measurement was performed, in the morning, on an empty stomach, on an InBody 370 measuring device, operating on the basis of electrical impedance.

\section{Organization and course of research}

All testing was performed in the Strength and Power Laboratory at the Jerzy Kukuczka Academy of Physical Education in Katowice. The tests were conducted in the afternoon after a light carbohydrate meal. Before the warm-up, the participants provided information on which limb is the back leg. Before the actual measurements, the subjects performed a 20-minute warm-up: running on a treadmill (5 minutes), riding a bicycle ergometer (10 minutes), strength exercises and dynamic stretching exercises involving the upper and lower body parts (5 minutes). The final element of the warm-up was work on the Keizer Leg Press measuring device according to the manufacturer's protocol, in which the knee bend between the thigh and the lower leg was 90 degrees. The 10RM test begins with the countdown on the user's display when the value reaches 0 . The device automatically increases the resistance by an average of $10 \%$ of the RM value and starts counting down the time to the next repetition. The pause time between the first repetitions is relatively short, and increases with increasing resistance. Based on this data, a 10 single repetition test was performed, where the first two repetitions were not taken into account and the value of the external resistance and the time to the next repetition were not changed to obtain the measurement data.

\section{STATISTICAL METHODS}

The obtained results were analyzed statistically. In order to determine the differences between individual weight categories and depending on the sports level in terms of the power generated in the lower back and front limbs, one-way ANOVA and post-hoc tests were used [12-14]. In order to determine differences within groups (weight category, sports level), Student's T-test was used. Statistical significance was set at $\mathrm{p}<0.05$. The calculations were made with the use of the STATISTICA 10 statistical package by StatSoft.

\section{RESULTS}

In the group of competitors of the 66-70 kg weight category, the analysis of data showed a constant deterioration of the value of the variable concerning the reaction time of the lower back limb (RTLBL) when increasing external resistance, in both studied groups. In the case of advanced fighters, a significant increase in the value of the variable occurred from $70 \%$ of the external resistance, while in the intermediate group - from 50\%. The growth dynamics was also slower in the advanced group (Figure 1).

With regard to the variable concerning the lower limb reaction time $\left(\mathrm{RT}_{\mathrm{LL}}\right)$, the data analysis showed a very similar increase and its dynamics as in the case of $\mathrm{RT}_{\mathrm{LBL}}$ (Figure 2). 


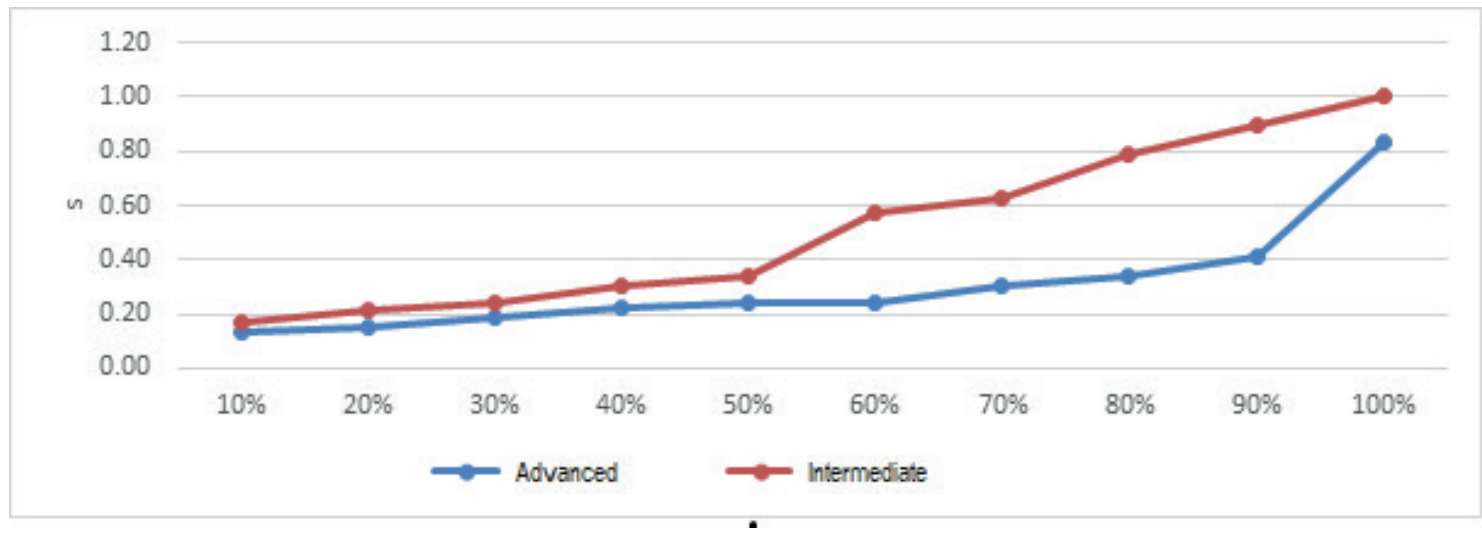

Fig. 1. Comparison of the dynamics of changes - the value for the variable RTLBL advanced and intermediate players in the $66-70 \mathrm{~kg}$ weight category

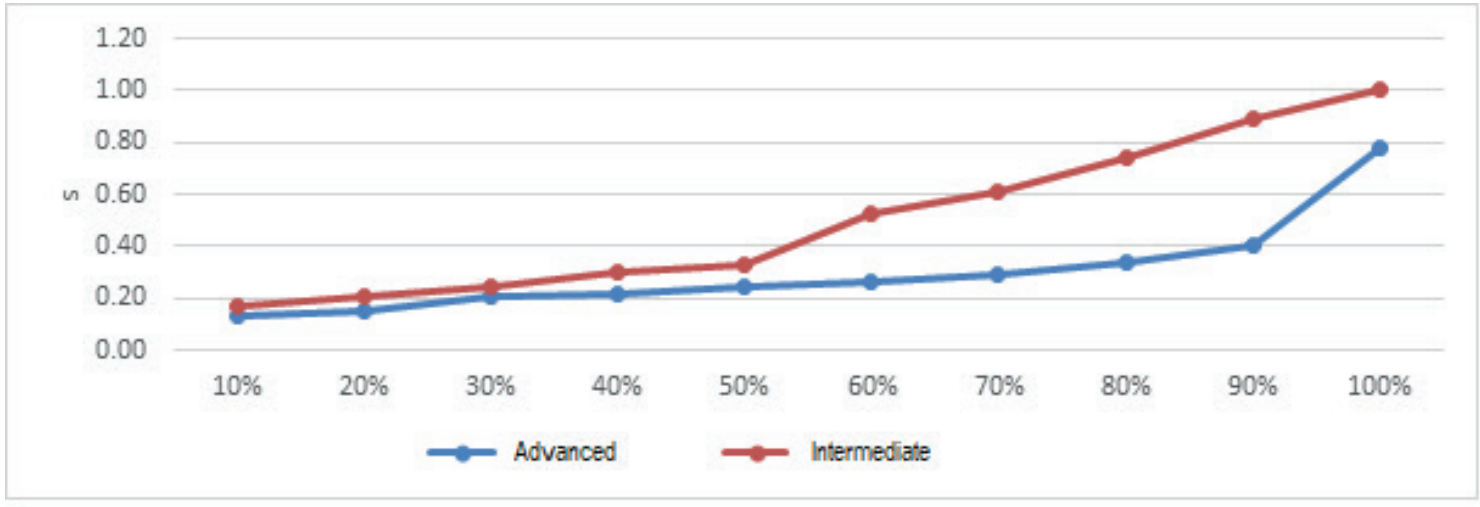

Fig. 2. Comparison of the dynamics of changes - the value for the variable $\mathrm{RT}_{\mathrm{LL}}$ of advanced and intermediate players in the $66-70 \mathrm{~kg}$ weight category

Table 1 presents the results of the index analysis for the $\mathrm{RT}_{\mathrm{LBL}}$ and $\mathrm{RT}_{\mathrm{LL}}$ variables in the group of advanced competitors in the $66-70 \mathrm{~kg}$ weight category, taking into account relative gains. The highest relative increase, constant in the range of the value of the $\mathrm{RT}_{\mathrm{LBL}}$ variable for $10 \%$ of the external resistance, was recorded at $90 \%$ and $100 \%$ load. The highest relative chain increase in the value of the $\mathrm{RT}_{\mathrm{LBL}}$ variable was recorded for $70 \%$ and $100 \%$ of the external resistance value, in relation to the preceding load. Similarly, for the $\mathrm{RT}_{\mathrm{LL}}$ variable in the group of advanced fighters, the highest relative constant increase in its value was recorded at $90 \%$ and $100 \%$ load. Taking into account the relative chain increment, the largest increase in the value of the $\mathrm{RT}_{\mathrm{LL}}$ variable took place for $30 \%$ and $100 \%$ of the external resistance value, in relation to the preceding load.

Table 2 presents the results of the index analysis for the $\mathrm{RT}_{\mathrm{LBL}}$ and $\mathrm{RT}_{\mathrm{LL}}$ variables in the group of intermediate competitors in the 66-70 kg weight category, taking into account relative gains. The highest relative increase, constant in the range of the value of the $\mathrm{RT}_{\mathrm{LBL}}$ variable with reference to $10 \%$ of the external resistance, was recorded at $90 \%$ and $100 \%$ load. Based on the calculated relative chain increment, the largest increase in the value of the $\mathrm{RT}_{\mathrm{LBL}}$ variable was recorded for $60 \%$ of the external resistance value, in relation to the preceding load, and a decrease for $70 \%$ of the external resistance. For the $\mathrm{RT}_{\mathrm{LL}}$ variable in the group of intermediate fighters, the largest increases in indices with a fixed base were recorded at $90 \%$ and $100 \%$ load. On the other hand, the highest relative chain increase in the value of the $\mathrm{RT}_{\mathrm{LL}}$ variable was recorded for $60 \%$ of the external resistance value, in relation to the preceding load, and the decrease for $70 \%$ of the external resistance (Figure 4). 
Table 1. Dynamics of changes in $\mathrm{RT}_{\mathrm{LBL}}$ and $\mathrm{RT}_{\mathrm{LL}}$ in the group of advanced players in the weight category 66-70 $\mathrm{kg}$, taking into account relative gains.

\begin{tabular}{|c|c|c|c|c|c|c|c|c|c|c|}
\hline 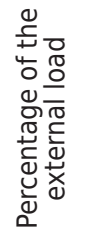 & 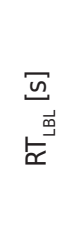 & 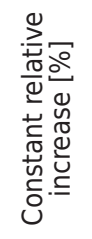 & $\stackrel{*}{2}$ & 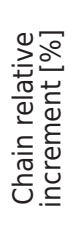 & 苔 & $\begin{array}{l}\widetilde{\Xi} \\
\stackrel{\Xi}{\sim}\end{array}$ & 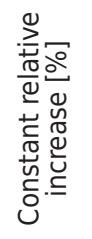 & $\stackrel{*}{2}$ & 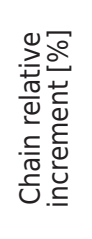 & $\stackrel{*}{2}$ \\
\hline $10 \%$ & 0,13 & 0 & 0 & 0 & 0 & 0.13 & 0 & 0 & 0 & 0 \\
\hline $20 \%$ & 0,15 & 15.2 & $<0.05$ & 15.2 & $<0.05$ & 0.15 & 15.0 & $<0.05$ & 15.0 & $<0.05$ \\
\hline $30 \%$ & 0,19 & 40.5 & $<0.05$ & 6.8 & $<0.05$ & 0.21 & 56.3 & $<0.05$ & 20.9 & $>0.05$ \\
\hline $40 \%$ & 0,22 & 65.8 & $<0.05$ & -4.0 & $<0.05$ & 0.21 & 60.0 & $<0.05$ & -33.5 & $<0.05$ \\
\hline $50 \%$ & 0,24 & 82.3 & $<0.05$ & -8.1 & $<0.05$ & 0.25 & 83.8 & $<0.05$ & 12.4 & $<0.05$ \\
\hline $60 \%$ & 0,25 & 86.1 & $<0.05$ & -7.8 & $>0.05$ & 0.26 & 96.3 & $<0.05$ & -8.0 & $<0.05$ \\
\hline $70 \%$ & 0,30 & 127.8 & $<0.05$ & 20.4 & $<0.05$ & 0.29 & 118.8 & $<0.05$ & 4.7 & $<0.05$ \\
\hline $80 \%$ & 0,34 & 158.2 & $<0.05$ & -9.1 & $<0.05$ & 0.34 & 151.3 & $<0.05$ & 3.4 & $>0.05$ \\
\hline $90 \%$ & 0,41 & 212.7 & $<0.05$ & 7.7 & $<0.05$ & 0.40 & 202.5 & $<0.05$ & 5.5 & $>0.05$ \\
\hline $100 \%$ & 0,84 & 534.2 & $<0.05$ & 81.8 & $<0.05$ & 0.78 & 481.3 & $<0.05$ & 71.8 & $<0.05$ \\
\hline
\end{tabular}

$* \mathrm{P}$ values have been calculated according to constant relative increments and chain relative increments.

Table 2. Dynamics of changes in $\mathrm{RT}_{\mathrm{LBL}}$ and $\mathrm{RT}_{\mathrm{LL}}$ in the group of intermediate players in the weight category 66-70 $\mathrm{kg}$, taking into account relative gains

\begin{tabular}{|c|c|c|c|c|c|c|c|c|c|c|}
\hline 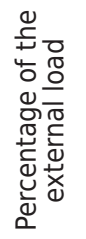 & 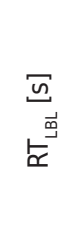 & 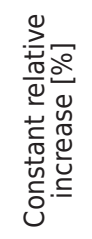 & $\stackrel{*}{2}$ & 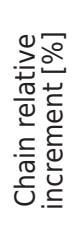 & 莒 & $\begin{array}{l}\widetilde{\Xi} \\
\stackrel{\Xi}{\simeq}\end{array}$ & 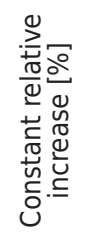 & $\stackrel{*}{2}$ & 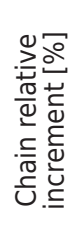 & $\stackrel{*}{2}$ \\
\hline $10 \%$ & 0.17 & 0 & 0 & 0 & 0 & 0.17 & 0 & 0 & 0 & 0 \\
\hline $20 \%$ & 0.21 & 24.8 & $<0.05$ & 24.8 & $<0.05$ & 0.21 & 22.1 & $<0.05$ & 22.1 & $<0.05$ \\
\hline $30 \%$ & 0.24 & 43.6 & $<0.05$ & -9.7 & $<0.05$ & 0.25 & 41.3 & $<0.05$ & -6.4 & $<0.05$ \\
\hline $40 \%$ & 0.30 & 78.2 & $<0.05$ & 9.1 & $<0.05$ & 0.30 & 74.0 & $<0.05$ & 7.4 & $<0.05$ \\
\hline $50 \%$ & 0.34 & 101.0 & $<0.05$ & -11.4 & $<0.05$ & 0.33 & 91.3 & $<0.05$ & -13.2 & $<0.05$ \\
\hline $60 \%$ & 0.57 & 240.6 & $<0.05$ & 56.7 & $<0.05$ & 0.53 & 205.8 & $<0.05$ & 49.9 & $<0.05$ \\
\hline $70 \%$ & 0.63 & 274.3 & $<0.05$ & -59.6 & $<0.05$ & 0.61 & 251.9 & $<0.05$ & -44.7 & $<0.05$ \\
\hline $80 \%$ & 0.79 & 368.3 & $<0.05$ & 15.2 & $<0.05$ & 0.74 & 326.0 & $<0.05$ & 5.9 & $<0.05$ \\
\hline $90 \%$ & 0.89 & 430.7 & $<0.05$ & -11.8 & $<0.05$ & 0.89 & 412.5 & $<0.05$ & -0.7 & $<0.05$ \\
\hline $100 \%$ & 1.01 & 497.6 & $<0.05$ & -0.7 & $<0.05$ & 1.01 & 481.3 & $<0.05$ & -6.9 & $<0.05$ \\
\hline
\end{tabular}

$* \mathrm{P}$ values have been calculated according to constant relative increments and chain relative increments.

Data analysis showed a clear upward trend in the averaged values of the $\mathrm{RT}_{\mathrm{LBL}}$ variable from the value of $80 \%$ of the external resistance in both studied groups. In the case of advanced fighters, the growth dynamics was greater than the value of $60 \%$ of the load and increased over the mentioned $80 \%$. Among intermediate advanced fighters, an increase in dynamics and a positive trend were noticed from the value of $80 \%$, with the increase between $70 \%-80 \%$ remaining at a similar level (Figure 3).

With regard to the averaged values of the $\mathrm{RT}_{\mathrm{LL}}$ variable, the data analysis showed a similar increase with a similar range of external resistance. Both groups showed a continuous increase with a positive trend to $90 \%$ of the external resistance. Then, a negative trend was observed and a sharp decline after exceeding $90 \%$ of the external resistance (Figure 4 ). 


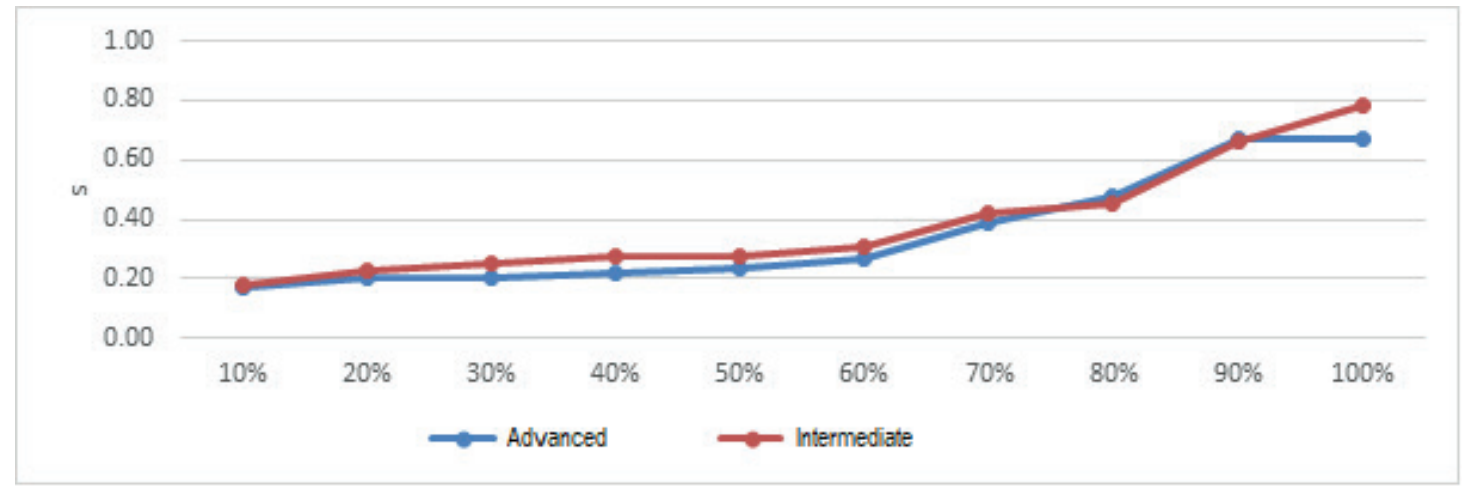

Fig. 3. Comparison of the dynamics of changes - the value for the RTLBL variable of advanced and intermediate players in the weight category above $93 \mathrm{~kg}$

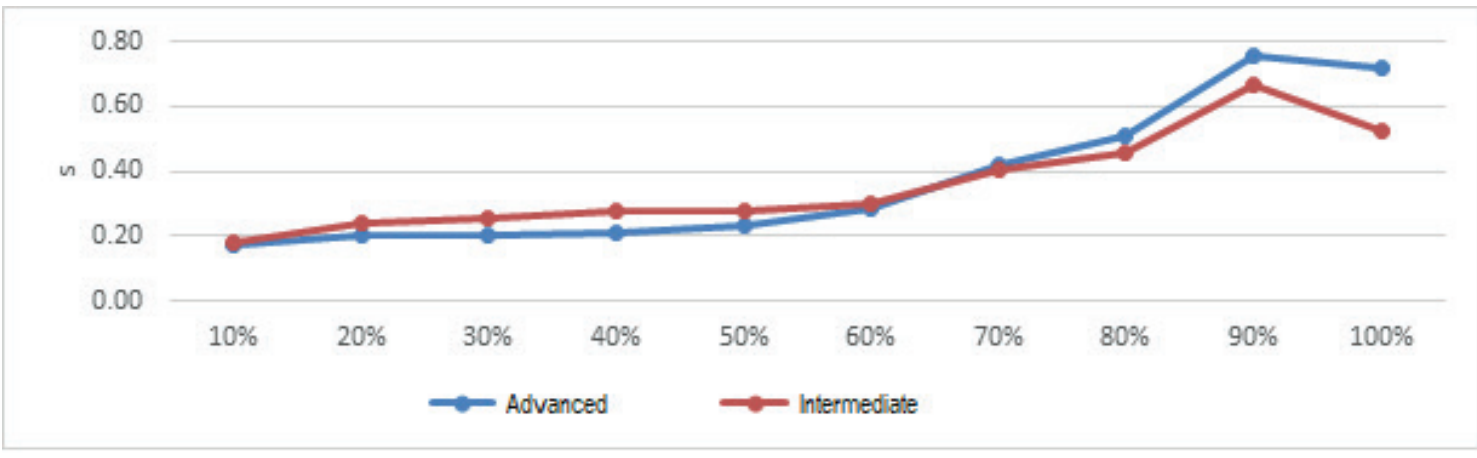

Fig. 4. Comparison of the dynamics of changes - the value for the variable $\mathrm{RT}_{\mathrm{LL}}$ of advanced and intermediate players in the weight category above $93 \mathrm{~kg}$

Table 3 presents the results of the index analysis for the $\mathrm{RT}_{\mathrm{LBL}}$ and $\mathrm{RT}_{\mathrm{LL}}$ variables in the group of advanced competitors in the weight category over $93 \mathrm{~kg}$, taking into account relative gains. The highest relative increase, constant in the range of the value of the $\mathrm{RT}_{\mathrm{LBL}}$ variable with respect to $10 \%$ of the external resistance, was recorded at $90 \%$ and $100 \%$ load. The highest relative chain increase in the value of the $\mathrm{RT}_{\mathrm{LBL}}$ variable was recorded for $70 \%$ of the external resistance, in relation to the preceding load. The greatest decrease in the value of the variable was for $100 \%$ external load. Similarly, for the $\mathrm{RT}_{\mathrm{LL}}$ variable in the group of advanced fighters, the highest relative constant increase in its value was recorded at $90 \%$ and $100 \%$ load. On the other hand, the largest relative chain increment in the value of the $\mathrm{RT}_{\mathrm{LL}}$ variable took place for $90 \%$ of the external resistance, in relation to the preceding load. The greatest decrease in the value of the variable was for $100 \%$ external resistance.

Table 4 presents the results of the index analysis for the $\mathrm{RT}_{\mathrm{LBL}}$ and $\mathrm{RT}_{\mathrm{LL}}$ variables in the group of intermediate competitors in the weight category over $93 \mathrm{~kg}$, taking into account relative gains. The highest relative increase, constant in the range of the value of the $\mathrm{RT}_{\mathrm{LL}}$ variable with reference to $10 \%$ of the external resistance, was recorded at $90 \%$ and $100 \%$ load. Based on the calculated relative chain increment, the highest increase in the value of the $\mathrm{RT}_{\mathrm{LBL}}$ variable was recorded for $90 \%$ of the external resistance value, in relation to the preceding load. The greatest decrease in the value of the variable for $80 \%$ of the external resistance.

For the $\mathrm{RT}_{\mathrm{LL}}$ variable in the group of intermediate fighters, the highest relative constant increase was recorded at $90 \%$ load. The highest relative chain increase in the value of the 
$\mathrm{RT}_{\mathrm{LL}}$ variable took place for $90 \%$ of the external resistance, in relation to the preceding load. The greatest decrease in the value of the variable was for $100 \%$ external resistance.

Table 3. Dynamics of $\mathrm{RT}_{\mathrm{LBL}}$ and $\mathrm{RT}_{\mathrm{LL}}$ changes in the group of advanced players in the weight category above 93 $\mathrm{kg}$, taking into account relative gains

\begin{tabular}{|c|c|c|c|c|c|c|c|c|c|c|}
\hline 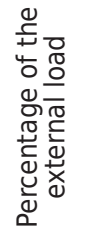 & 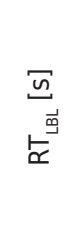 & 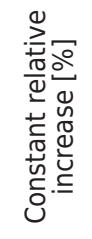 & * & 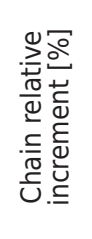 & 苔 & $\begin{array}{l}\bar{\Xi} \\
\underline{\Xi}^{\prime}\end{array}$ & 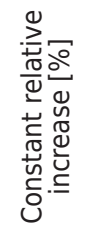 & * & 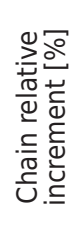 & * \\
\hline $10 \%$ & 0.17 & 0 & 0 & 0 & 0 & 0.17 & 0 & 0 & 0 & 0 \\
\hline $20 \%$ & 0.20 & 19.0 & $<0.05$ & 19.0 & $<0.05$ & 0.20 & 16.5 & $<0.05$ & 16.5 & $<0.05$ \\
\hline $30 \%$ & 0.20 & 21.0 & $<0.05$ & -17.3 & $<0.05$ & 0.20 & 17.5 & $<0.05$ & -15.7 & $<0.05$ \\
\hline $40 \%$ & 0.22 & 30.0 & $<0.05$ & 5.8 & $<0.05$ & 0.21 & 23.3 & $<0.05$ & 4.1 & $<0.05$ \\
\hline $50 \%$ & 0.23 & 39.0 & $<0.05$ & -0.5 & $<0.05$ & 0.23 & 34.0 & $<0.05$ & 3.7 & $>0.05$ \\
\hline $60 \%$ & 0.27 & 62.0 & $<0.05$ & 9.6 & $<0.05$ & 0.29 & 66.0 & $<0.05$ & 15.3 & $>0.05$ \\
\hline $70 \%$ & 0.39 & 134.0 & $<0.05$ & 27.9 & $<0.05$ & 0.42 & 143.7 & $<0.05$ & 22.9 & $>0.05$ \\
\hline $80 \%$ & 0.48 & 186.0 & $<0.05$ & -22.2 & $<0.05$ & 0.51 & 196.1 & $<0.05$ & -25.3 & $<0.05$ \\
\hline $90 \%$ & 0.67 & 301.0 & $<0.05$ & 18.0 & $<0.05$ & 0.76 & 339.8 & $<0.05$ & 27.0 & $<0.05$ \\
\hline $100 \%$ & 0.67 & 300.8 & $<0.05$ & -40.3 & $<0.05$ & 0.72 & 319.8 & $<0.05$ & -53.1 & $<0.05$ \\
\hline
\end{tabular}

* $\mathrm{P}$ values have been calculated according to constant relative increments and chain relative increments.

Table 4. Dynamics of changes in $\mathrm{RT}_{\mathrm{LBL}}$ and $\mathrm{RT}_{\mathrm{LL}}$ in the group of intermediate players in the weight category 66-70 $\mathrm{kg}$, taking into account relative gains

\begin{tabular}{|c|c|c|c|c|c|c|c|c|c|c|}
\hline 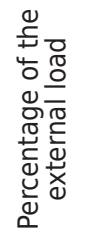 & 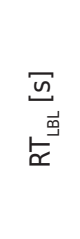 & 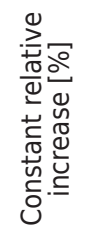 & $\stackrel{*}{2}$ & 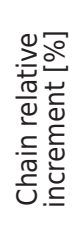 & * & 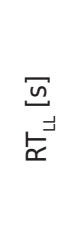 & 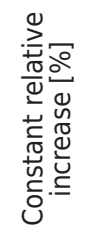 & $\stackrel{*}{2}$ & 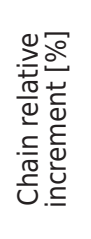 & $\stackrel{*}{2}$ \\
\hline $10 \%$ & 0.18 & 0 & 0 & 0 & 0 & 0.18 & 0 & 0 & 0 & 0 \\
\hline $20 \%$ & 0.23 & 27.8 & $<0.05$ & 27.8 & $<0.05$ & 0.24 & 30.9 & $<0.05$ & 30.9 & $<0.05$ \\
\hline $30 \%$ & 0.25 & 39.8 & $<0.05$ & -18.4 & $<0.05$ & 0.25 & 38.2 & $<0.05$ & -25.4 & $<0.05$ \\
\hline $40 \%$ & 0.28 & 53.7 & $<0.05$ & 0.5 & $<0.05$ & 0.28 & 50.9 & $<0.05$ & 3.7 & $<0.05$ \\
\hline $50 \%$ & 0.27 & 51.9 & $<0.05$ & -11.1 & $<0.05$ & 0.28 & 52.7 & $<0.05$ & -8.0 & $>0.05$ \\
\hline $60 \%$ & 0.31 & 72.2 & $<0.05$ & 14.6 & $<0.05$ & 0.30 & 64.5 & $<0.05$ & 6.5 & $>0.05$ \\
\hline $70 \%$ & 0.42 & 135.2 & $<0.05$ & 23.1 & $>0.05$ & 0.41 & 120.9 & $<0.05$ & 26.5 & $>0.05$ \\
\hline $80 \%$ & 0.45 & 150.0 & $<0.05$ & -30.3 & $<0.05$ & 0.46 & 148.2 & $<0.05$ & -21.9 & $<0.05$ \\
\hline $90 \%$ & 0.66 & 267.6 & $<0.05$ & 40.7 & $<0.05$ & 0.67 & 262.7 & $<0.05$ & 33.8 & $<0.05$ \\
\hline $100 \%$ & 0.79 & 337.3 & $<0.05$ & -28.1 & $<0.05$ & 0.52 & 185.5 & $<0.05$ & -67.4 & $<0.05$ \\
\hline
\end{tabular}

$* \mathrm{P}$ values have been calculated according to constant relative increments and chain relative increments.

The analysis of variance ANOVA with repeated measurements showed no significant differences between the chain increments of the $\mathrm{RT}_{\mathrm{LBL}}$ and $\mathrm{RT}_{\mathrm{LL}}$ variables depending on the weight category and the research group (Table 5). 
Table 5. The result of the analysis of variance of the $\mathrm{RT}_{\mathrm{LBL}}$ and $\mathrm{RT}_{\mathrm{LL}}$ variables depending on the weight category and the level of training of the competitor

\begin{tabular}{|c|c|}
\hline Analyzed variable & $\mathrm{p}$ \\
\hline $\mathrm{RT}_{\text {LBL }}$ vS $\mathrm{RT}_{\mathrm{LL} \_} 66 \mathrm{~kg}$ - advanced & 0,929 \\
\hline $\mathrm{RT}_{\text {LBL }}$ vs $\mathrm{RT}_{\text {LL _ }} 66 \mathrm{~kg}$ - intermediate & 0,994 \\
\hline $\mathrm{RT}_{\text {LBL }}$ vs $\mathrm{RT}_{\mathrm{LL} \_}{ }_{-} 93 \mathrm{~kg}$ - advanced & 0,965 \\
\hline $\mathrm{RT}_{\text {LBL }}$ VS $\mathrm{RT}_{\mathrm{LL} \_} 93 \mathrm{~kg}$ - intermediate & 0,752 \\
\hline $\mathrm{RT}_{\text {LBL }}-66 \mathrm{~kg}$ vs. $93 \mathrm{~kg}$ - advanced & 0,960 \\
\hline $\mathrm{RT}_{L L}-66 \mathrm{~kg}$ vs. $93 \mathrm{~kg}$ - advanced & 0,412 \\
\hline $\mathrm{RT}_{\text {LBL }}-66 \mathrm{~kg}$ vs. $93 \mathrm{~kg}$ - intermediate & 0,960 \\
\hline $\mathrm{RT}_{\mathrm{LL}}-66 \mathrm{~kg}$ vs. $93 \mathrm{~kg}$ - intermediate & 0,784 \\
\hline
\end{tabular}

\section{DISCUSSION}

Many factors affect a player's reaction time, including fatigue, the level of stimulation of non-specific structures of the nervous system, age, sex, mental state, stress, circadian cycle, nutrition, drug use, genetic conditions, as well as individual predispositions [15-17]. There are two types of perceptual abilities related to sports performance. The first one is based on primitive, basic sensory functions that are unrelated to an athlete's area of specialization and include factors such as visual acuity and visual field [4]. Training specific to these skills is not believed to improve athletic performance [4, 18-20]. The second type involves sport-specific sensory skills developed during sport training. The simple response time is the shortest time required to respond to a single stimulus. Most reports showed differences in the simple reaction time between athletes and recreational training to the benefit of athletes [21-22]. However, some reports did not detect differences in the time of the simple reaction, suggesting that this parameter is not amenable to training [4]. From the results of our own research, no significant statistical differences were also found in the reaction time of the lower limbs between advanced and intermediate fighters with percentages from $10-100 \%$ of the external resistance in both weight categories.

In this study, the greatest difference (statistically insignificant) in the reaction time between the front limb and the back limb, and the greatest constant relative gain (\%) with the use of resistances exceeding $90 \%$ and up to $100 \%$ of the maximum weight in both weight categories, was found. The results of own research allow for the conclusion that training of maximum strength capabilities allows detecting the dominance of one lower limb, athletes' endurance and their resistance to fatigue. Ruchan [23], who analyzed the impact of fatigue of elite Turkish wrestlers on the reaction time immediately before and after sports competition, found a (statistically insignificant) relationship between the variable at rest and the variable after a sports fight, where the reaction time before the competition ( $227.62 \pm 64.71 \mathrm{~ms}$ ) was shorter than immediately after the competition $(280.37 \pm 64.71 \mathrm{~ms})$. There are several similar studies in the literature in which the reaction time immediately after loading with 40\% 1RM, 60\% 1RM and 80\% 1RM was analyzed among athletes practicing tennis, boxing and table tennis, and they showed that the reaction time was extended [24].

The obtained results of this research indicate a constant deterioration of the value of the $\mathrm{RT}_{\mathrm{LBL}}$ and $\mathrm{RT}_{\mathrm{LL}}$ variable with increasing external resistance in both studied groups. In the case of advanced fighters in the 66-70 kg weight group, a clear (statistically significant) increase in the value of the $\mathrm{RT}_{\mathrm{LBL}}$ and $\mathrm{RT}_{\mathrm{LL}}$ variable occurred from $70 \% 1 \mathrm{RM}$, while in the intermediate group it was from 50\% $1 \mathrm{RM}$, and from $80 \% 1 \mathrm{RM}$ in the weight category above 93 in both study groups. Growth dynamics was lower in the advanced group in both tested weight categories. The results of own research allow concluding that less 
experienced fighters feel fatigue faster than more experienced ones and have a shorter reaction time (no statistical significance). Similar conclusions were made by Johne et al. [25] in research on the asymmetry of complex reaction time of epee-lesions of varying degrees of advancement using the RT Test (Reaction Time, form S5). On the basis of the obtained results, it was found that the competitors with a higher sports class had a shorter reaction time.

Also in Borysiuk's research [26] on fencers, the obtained results indicate a shorter simple reaction time in the more experienced athletes, classified in the International Fencing Federation (FIE) / Olympic group (average age $=23.28$ ) than in the athletesclassified in the Polish Federation Fencing / junior groups (average age $=17.23$ ), and than in the case of competitors classified in the Silesian Fencing Association (average age $=14.52$ ).

In this research, ANOVA analysis of variance with repeated measurements showed no significant differences between the chain increments of the $\mathrm{RT}_{\mathrm{LBL}}$ and $\mathrm{RT}_{\mathrm{LL}}$ variable depending on the weight category and the research group.

\section{CONCLUSIONS}

The obtained results of motor tests can be used to optimize the training process of MMA fighters. Performing the progression of the external resistance on the Keizer Leg Press A420 pneumatic device enabled accurately determining the dynamics of differences in the reaction time of the back limb and front limb in MMA fighters. The use of resistances exceeding $90 \%$ and reaching $100 \%$ of the maximum weight allows detecting the dominance of one lower limb. Taking into account the individual weight categories, sports level, muscle strength, reaction time and individual motor potential, the authors of this article conclude that the dynamics and nature of the fight may significantly differ depending on the above-mentioned factors.

\section{REFERENCES}

[1] Mori S, Ohtani Y, Imanaka K. Reaction times and anticipatory skills of karate athletes. Hum Movement Sci. 2002;21:213-230. https://doi.org/10.1016/S0167-9457(02)00103-3

[2] Neto OP, Bolander R, Pacheco MT, Bir C. Force, reaction time, and precision of Kung Fu strikes. Percept Motor Skills. 2009;109:295-303. https://doi.org/10.2466/pms.109.1.295-303

[3] Bianco M, Ferri M, Fabiano C, Giorgiano F, Tavella S. Baseline simple and complex reaction times in female compared to male boxers. J Sport Med Physical Fitness. 2001;51:292-298.

[4] Borysiuk Z, Waskiewicz Z. Information Processes, Stimulation and Perceptual Training in Fencing. J Hum Kinetics. 2008;19:63-82. https://doi.org/10.2478/v10078-008-0005-y

[5] Loturco I, Franchini E, Cavinato Cal Abad C, et al. Comparative study of specific reaction time in elite boxers: Differences between jabs and crosses. J Athletic Enhance. 2015;4:3-5.

[6] Ando S, Kida N, Oda S. Practice effects on reaction time for peripheral and central visual fields. Percept Motor Skills. 2002;3:747-752. https://doi.org/10.2466/pms.2002.95.3.747

[7] Hugues M, Franks I. Analysis of passing sequences, shots and goals in soccer. J Sport Sci. 2005;5:09-514. https:// doi.org/10.1080/02640410410001716779

[8] Gore S, Richter C, Marshall B, et al. A comparison of asymmetry in athletic groin pain patients and elite rugby union players using analysis of characterizing phases. Int Conference Biomech Sport. 2014;32:237-240.

[9] Maestas C, Preuhs RR. Modeling volatility in political time series. Electoral Stud. 2000;19:95-110. https://doi. org/10.1016/S0261-3794(99)00038-4

[10] Green M. How long does it take to stop? Methodological analysis of driver perception-brake time. Transport Hum Factors. 2000;2:195-216. https://doi.org/10.1207/STHF0203_1

[11] Keele L, Kelly NJ. Dynamic models for dynamic theories: The ins and outs of lagged dependent variables. Political Analysis. 2005;14:186-205. https://doi.org/10.1093/pan/mpj006

[12] Huciński T, Łapszo J, Tymański R, Zienkiewicz P. The relationship between the speed of motor reaction and shortdistance runs and the effectiveness of play in defence and offense in basketball. Kinesiology. 2007;39:157-164.

[13] Cojocariu A, Honceriu C. The effect of the specific training upon the values of the choice reaction time at the level of the upper limbs in the lawn tennis (16-18-year-old). Revista Sport si Societate. 2011;79:79-84.

[14] Nisiyama M, Ribeiro-do-Valle LE. Relative performance of the two hands in simple and choice reaction time tasks. Braz J Med Biol Res. 2014;47:80-89. https://doi.org/10.1590/1414-431X20132932 
[15] Wood JM, Abernethy B. An assessment of the efficacy of sports vision training programs. Optometry Vision Sci. 1997;74:646-659. https://doi.org/10.1097/00006324-199708000-00026

[16] Abernethy B, Neal RJ. Visual characteristics of clay target shooters. J Sci Med Sport. 1999;2:1-19. https://doi. org/10.1016/S1440-2440(99)80180-7

[17] Kandel ER, Schwarz JH, Jessell TM. Principals of neural science. New York: McGraw-Hill, 2021.

[18] Donovan O, Cheung J, Catley M, McGregor A, Strutton P. An investigation of leg and trunk strength and reaction times of hard-style martial arts practitioners. J Sci Sport Med. 2006;2:5-12.

[19] Bańkosz Z, Nawara H, Ociepa, M. Assessment of simple reaction time in badminton players. Trends Sport Sci. 2003; 1:54-61.

[20] Ruchan I, Zait A, Mustafa K, Ibrahim S, Fatih M. The effect of fatigue in elite young female wrestlers upon balance performance and reaction time. Biomed Res. 2016;4:1166-1170.

[21] Duvan A, Toros T, Senel O. Effects of maximum exercise intensity on visual reaction time of elite fencers. J Phys Educ Sport 2010; 4: 146-151.

[22] Johne M, Poliszczuk T, Poliszczuk D, Dybrowska-Perzyna A. Asymmetry of Complex reaction time in female épée fencers of different sports classes. Pol J Sport Tourism 2013; 20: 25-34. https://doi.org/10.2478/pjst-2013-0003

[23] Borysiuk Z. Struktura czasowa procesów informacyjnych w wybranych sportach walki. Warszawa: AWF, 2006 [Time structure of information processes in selected combat sports]. Polish. 